\title{
INVESTIGAÇÃO DE COLISÕES ENTRE AVES E AERONAVES NO BRASIL COM O USO DO DNA BARCODING
}

\author{
Carlos Benigno Vieira de Carvalho', Levy Heleno Fassio² e Renato Teodoro \\ Ferreira de Paranaíba ${ }^{3}$
}

\begin{abstract}
Resumo: Colisões entre aves e aeronaves são bastante frequentes, ameaçando vidas e causando perdas econômicas. A identificação das aves envolvidas nesses eventos pode ser importante para auxiliar as investigações de acidentes aéreos e subsidiar planos de manejo para reduzir os riscos em áreas críticas. Quando as aves envolvidas nas colisões não podem ser identificadas morfologicamente, pode ser empregado o DNA barcoding, sistema de identificação animal baseado em sequências padronizadas da subunidade I do gene mitocondrial da citocromo $C$ oxidase (COI) que variam entre espécies. Atualmente o sistema conta com uma plataforma informatizada, denominada BOLD, que engloba bancos de sequências de referência autenticadas e uma ferramenta de busca. Entre 2014 e 2018, o Laboratório de DNA da Polícia Federal recebeu do Centro de Investigação e Prevenção de Acidentes Aeronáuticos (CENIPA), para identificação, 109 materiais relacionados a 97 colisões distintas. O DNA Barcoding e o BOLD, juntamente com dados de ocorrência das espécies, possibilitaram a identificação de $83,5 \%$ dos materiais, apontando as aves envolvidas em $91,7 \%$ das colisões. Foram identificados 23 gêneros e espécies distintas, sendo Coragyps atratus, Caracara plancus, Vanellus chilensis e Fregata magnificens as mais frequentes. Poucas espécies estão envolvidas na maior parte das colisões e, assim, ações que tenham por objetivo diminuir o risco destes eventos devem priorizá-las.
\end{abstract}

Palavras-chave: DNA barcoding. Colisões. Aves. Aeronaves. Identificação.

\section{Introdução}

Colisões entre aves e aeronaves são bastante frequentes no mundo inteiro, colocando em risco as vidas das tripulações e passageiros e causando enormes perdas econômicas, tanto em termos de manutenção ou substituição dos equipamentos danificados quanto em horas em solo (ANDERSON et al., 2015). No período de 1990 a 2015 foram registradas 164.444 dessas colisões envolvendo aeronaves civis dos Estados Unidos, o que resultou em mais de 650 milhões de dólares em danos comunicados, 25 mortes e centenas de feridos (DOLBEER et al., 2015). No Brasil, apenas no ano de 2015 foram reportados 1733 impactos entre aves e aparelhos civis e militares (OLIVEIRA et al., 2016). Dados sobre vítimas e prejuízos no país são escassos, mas no ano de 2009 as empresas de aviação civil locais estimaram um gasto de 21 milhões de dólares decorrente desse tipo de incidente (RISCO ..., 2010).

A identificação de aves envolvidas em colisões pode ser importante por uma série de razões, incluindo o auxílio às investigações de acidentes aéreos, a melhoria ou verificação da conformidade dos projetos e peças das aeronaves, e para subsidiar planos de manejo ambiental que tenham por objetivo reduzir os riscos de impactos em áreas críticas, tais como na proximidade dos aeroportos (DOVE et al., 2008; DOVE; DAHLAN; HEACKER, 2009). A remoção de determinadas espécies ou os recursos utilizados por elas das áreas aeroportuárias, bem como o controle do uso da terra e a regulamentação de atividades econômicas que têm potencial para atrair aves nas áreas adjacentes, são ações que podem reduzir bastante a frequência das colisões entre estes animais e aeronaves (ALLAN 2000; SODHI 2002).

Tradicionalmente a identificação de aves que colidem com aeronaves é feita com base na sua morfologia, incluindo análises macro e microscópicas das plumas e penas (DOVE et al., 2008; DOVE; DAHLAN; HEACKER, 2009). No entanto, quando os restos biológicos disponíveis para análises se restringem a manchas de sangue, pequenos

\footnotetext{
1E-mail: benigno.cbvc@dpf.gov.br

Área de Perícias em Genética Forense, Instituto Nacional de Criminalística, Diretoria Técnico-Científica, Polícia Federal. Setor Policial Sul, Quadra 7, Lote 23, sala F-217, Brasília-DF. CEP 70610-200.

²E-mail: heleno.Ihf@dpf.gov.br

${ }^{3}$ E-mail: renato.rtfp@dpf.gov.br
} 
REA - Revista de estudos ambientais (Online)

v.21, n. 2, p.71-79, jul./dez. 2019

fragmentos de penas, vísceras ou outros tecidos, que é o tipo de material que normalmente resta após uma colisão, é necessária uma outra abordagem. Em tais situações podem ser empregadas técnicas de identificação genética, como por exemplo aquela que possibilita a associação de amostras questionadas a amostras de referência por meio da comparação de sequências de DNA que variam entre espécies (DANWAY et al., 2007). Devido às suas características, como estar presente em um grande número de cópias no interior das células, sendo facilmente detectável, e apresentar altas taxas de mutação, o que permite a diferenciação de espécies próximas, o DNA mitocondrial é utilizado rotineiramente como fonte de sequências para fins de identificação animal (OGDEN; DANWAY; MCEWING, 2009; ALACS et al., 2010; LINACRE; TOBE, 2011; JOHNSON; WILSON-WILDE; LINACRE, 2014).

Proposto originalmente em 2003, o DNA barcoding foi concebido para ser um sistema universal de catalogação e identificação de espécies animais baseado em sequências padronizadas da subunidade I do gene mitocondrial da citocromo $\mathrm{C}$ oxidase (COI), sendo que a sua adequação para diferenciar um grande número de espécies de aves já foi demonstrada (HERBERT; RATNASINGHAM; WAARD, 2003, HERBERT et al., 2004, TAVARES et al., 2011). O sistema foi descrito por Ratnasingham e Hebert (2007), e atualmente engloba uma plataforma informatizada denominada Barcode of Life Data System (BOLD) e outras funcionalidades, incluindo bancos de dados de sequências autenticadas depositadas por instituições científicas e uma ferramenta de busca utilizada para identificações. De acordo com os autores, a identificação específica normalmente ocorre quando o valor de similaridade entre uma sequência questionada e sequências de uma determinada espécie presente no banco de dados é superior a 99\%, com o gênero sendo apontado em casos onde a similaridade fica entre 97-99\%. Das cerca de 10 mil espécies de aves conhecidas, cerca de 5,7 mil estão representadas no BOLD (RATNASINGHAM; HEBERT, 2019). O DNA barcoding e o BOLD já foram utilizados de forma bem-sucedida para a identificação de aves envolvidas em colisões com aeronaves em outros países, incluindo os Estados Unidos e a Nova Zelândia (DOVE et al., 2008; WAUGH et al., 2011).
Em 2014, o Laboratório de DNA da Polícia Federal, em Brasília, iniciou um programa de cooperação com o Centro de Investigação e Prevenção de Acidentes Aeronáuticos (CENIPA). Também sediado na capital do país, o CENIPA é o órgão do Comando da Aeronáutica responsável pelas atividades de investigação de acidentes aeronáuticos envolvendo aeronaves civis e da Força Aérea Brasileira, com foco na prevenção de novas ocorrências. Desde o início da cooperação, restos de aves envolvidas em colisões com aeronaves em todo o território nacional, que não podem ser identificados morfologicamente são encaminhados ao laboratório para identificação genética, contribuindo para o esclarecimento dos fatos. Este trabalho detalha o uso do DNA barcoding e do BOLD, associados a dados de ocorrência de espécies, para a identificação de aves envolvidas nesse tipo de incidente no Brasil e apresenta os resultados obtidos até 0 momento.

\section{Metodologia}

Entre os anos de 2014 e 2018, o laboratório de DNA da Polícia Federal, em Brasília, examinou 109 materiais referentes a 97 eventos de colisões entre aves e aeronaves civis e militares ocorridas nas cinco regiões do Brasil. Em sua maioria, os materiais recebidos eram compostos de restos de penas e plumas, suabes com fluidos biológicos ou fragmentos de outros tecidos, tais como vísceras ou músculos, secos ou preservados em etanol. Pelo menos uma amostra de cada material foi selecionada para os exames, o que resultou em um total de 165 amostras. Estas foram compostas da totalidade dos suabes encaminhados ou de fragmentos com cerca de $0,3 \mathrm{~cm}$ de tecido muscular, vísceras ou da extremidade do cálamo das penas e plumas.

O DNA das amostras foi extraído com o kit de extração PrepFiler Express ${ }^{\mathrm{TM}}$ (Applied Biosystems) em um sistema robótico AutoMate Express ${ }^{\mathrm{TM}}$ (Applied Biosystems). Fragmentos de aproximadamente $650 \mathrm{pb}$ da região 5' do gene COI foram amplificados com a utilização dos iniciadores FishF1/FishR1 (WARD et al., 2005) e LCO1490/HCO2198 (FOLMER et al., 1994). As condições de PCR e sequenciamento foram as mesmas descritas por Carvalho (2014), com a diferença de que parte das sequências foi obtida em um analisador genético ABI 3500 
REA - Revista de estudos ambientais (Online)

v.21, n. 2, p.71-79, jul./dez. 2019

(Applied Biosystems). Da mesma forma, além daqueles descritos por Carvalho (2014) foram utilizados também os programas SeqScape 3 (LIFE TECHNOLOGIES CORPORATION, 2012), para a montagem e avaliação da qualidade das sequências, e MEGA 6 (TAMURA et al., 2013), para os alinhamentos e tradução, permitindo identificar a ocorrência de heteroplasmia ou de códons de parada estranhos. As sequências consensuais obtidas foram confrontadas com aquelas depositadas no banco de dados Species Level Barcode Records da plataforma BOLD com o uso de sua própria ferramenta de busca.

A identificação dos materiais recebidos foi baseada nos resultados de similaridade providos pelo BOLD, considerando-se a representatividade dos grupos identificados no referido banco e, quando necessário, também fazendo uso de dados sobre a ocorrência geográfica das espécies. A identificação até 0 nível taxonômico de espécie foi efetuada quando: (1) a sequência questionada apresentou mais de $99 \%$ de similaridade com sequências de uma única espécie no BOLD e todas as espécies congenéricas conhecidas se encontravam nele representadas; 2) a sequência questionada apresentou mais de 99\% de similaridade com sequências de uma única espécie no BOLD, na ausência de uma ou mais espécies congenéricas no banco, mas os dados de ocorrência, considerando o local da colisão, permitiram eliminá-la(s) como possibilidade(s); e 3) a sequência questionada apresentou mais de $99 \%$ de similaridade com sequências de mais de uma espécie no BOLD, na presença de todas ou na ausência de uma ou mais espécies congenéricas, mas os dados de ocorrência, considerando o local da colisão, permitiram eliminar todas menos uma das "espécies candidatas". Nas duas últimas situações, quando não foi possível utilizar os dados de ocorrência para chegar a apenas uma única espécie, a identificação foi efetuada até o nível de gênero. As informações taxonômicas, os dados sobre a ocorrência das espécies e os seus nomes populares foram obtidos em Gill e Donsker (2019), Sigrist (2009) e Piacentini et al. (2015).

\section{Resultados}

Sequências de boa qualidade para confronto foram obtidas de 129 das 165 amostras provenientes dos materiais examinados. A não obtenção de sequências apropriadas para análise pode ser atribuída à ausência ou à degradação do DNA existente no material, possivelmente uma consequência da exposição prolongada a condições ambientais inadequadas antes da coleta. É sabido que a exposição excessiva ao calor e à luz ultravioleta, por exemplo, são danosas ao DNA e podem interferir ou impossibilitar a sua análise (MICHELIN; FREITAS; KORTMANN, 2013). Com exceção de uma única sequência (com 98,45\%), todos os confrontos resultaram em valores de similaridade maiores do que $99 \%$ com sequências de pelo menos uma espécie no banco de dados utilizado. Vinte e oito sequências apresentaram mais de $99 \%$ de similaridade com sequências de mais de uma espécie no banco. Com base na metodologia proposta foi possível identificar 91 (83,5\%) dos 109 materiais recebidos, sendo 88 deles até o nível de espécie. Dados de ocorrência das espécies foram utilizados em conjunto com os resultados do BOLD para a identificação específica de 48 materiais (Figura 1). Dois dos três casos onde a identificação foi feita até o nível de gênero resultaram da impossibilidade de eliminar com os dados de ocorrência geográfica espécies congenéricas (Cypseloides) não representadas no BOLD, apesar da sequência ter apresentado similaridade superior a $99 \%$ com uma única espécie no banco. No terceiro caso, a sequência questionada apresentou mais de $99 \%$ de similaridade com duas espécies distintas (Caracara plancus e C. cheriway) e, mais uma vez, os dados de ocorrência não puderam ser utilizados para eliminar uma delas.

A maior parte dos materiais foi associada à uma única espécie ou gênero. Houve apenas um caso em que o material examinado, representado por um conjunto de suabes de uma mesma mancha coletada na aeronave, foi associado à duas espécies diferentes, o que provavelmente foi resultante de dois impactos distintos na mesma parte do aparelho. Tendo em vista que as duas espécies envolvidas, Vanellus chilensis e Coturnix coturnix, não predam outras aves, uma contaminação oriunda da exposição do conteúdo estomacal de uma delas após o impacto pode ser descartada. Vinte e três espécies ou gêneros distintos foram identificados no total, sendo que Coragyps atratus, Caracara plancus, Vanellus chilensis e Fregata magnificens foram as espécies mais frequentes. Foram identificadas as aves 


\section{REA - Revista de estudos ambientais (Online) v.21, n. 2, p.71-79, jul./dez. 2019}

envolvidas em 89 (91,7\%) dos 97 eventos de colisões (Tabela 1).

As identificações obtidas permitem avaliar que, considerando o território brasileiro como um todo, poucas espécies são responsáveis pela maior parte dos impactos. Um grande número de outras espécies, portanto, parece oferecer um risco menor, tendo em vista a baixa probabilidade de seu envolvimento em colisões. É importante ressaltar, no entanto, que devido a características ambientais distintas, são esperadas diferenças regionais e locais com relação à avifauna envolvida nestes eventos, e que esta deve ser identificada por meio de estudos específicos. De qualquer forma, ações que tenham por objetivo diminuir o problema dos choques entre aves e aeronaves devem priorizar o controle das espécies mais frequentemente envolvidas em tais episódios, especialmente nas áreas de risco. Apesar de algumas ressalvas com relação aos dados, uma vez que é sabido que muitas ocorrências não são reportadas, 90\% dos choques entre aves e aeronaves civis são registrados perto de aeroportos $(\mathrm{SODHI}$, 2002).

De acordo com Martos e Madeira (2013), a intensidade dos danos e das lesões decorrentes das colisões dependem basicamente da velocidade da aeronave e da massa da ave. Os resultados mostram que três das espécies mais frequentemente envolvidas em impactos com aeronaves foram Coragyps atratus, Caracara plancus e Fregata magnificens, aves de porte considerável. Com massa em torno de $1 \mathrm{~kg} \mathrm{e}$ atingindo cerca de $50 \mathrm{~cm}$ de comprimento, no caso de $C$. atratus e $C$. plancus, e mais de 1 $\mathrm{m}$, no caso de F. magnificens (SIGRIST, 2009; MENQ 2018), estas aves têm potencial para causar grandes estragos nos aparelhos envolvidos. Operadores e tripulações de aeronaves trafegando por áreas com maior incidência desses animais devem ser informados a respeito dos riscos existentes para que adotem as precauções adequadas.

Figura 1 - Identificação dos materiais recebidos segregados por nível taxonômico, considerando-se ou não a utilização de dados de ocorrência geográfica das espécies ( $n=109)$

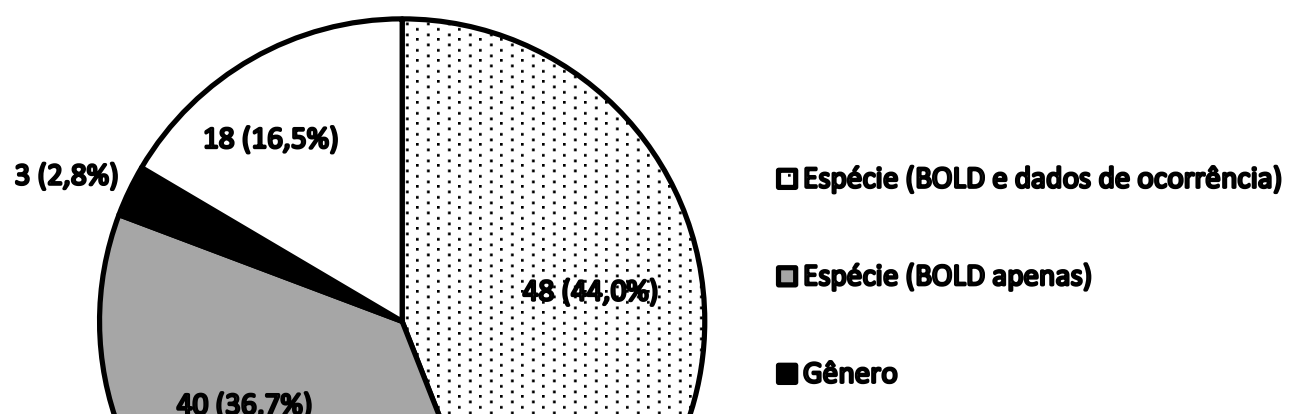

口Não identificado

Fonte: Autores (2019)

As espécies $C$. atratus e $C$. plancus sozinhas responderam por mais de $50 \%$ dos eventos de colisões aqui analisados. Ambas as espécies habitam áreas urbanas e são oportunistas, muitas vezes utilizando lixo como fonte de alimentos (SIGRIST, 2009; OLIVEIRA; SOUZA; SILVA; 2014). De fato, em um estudo recente, Araujo et al. (2018) mostraram que a falta de procedimentos adequados para a armazenagem de resíduos sólidos pode estar relacionada com 0 aumento da ocorrência e da abundância de $C$. atratus em áreas urbanas. Sendo assim, para diminuir o risco de impactos entre aeronaves e estes animais, é fundamental que nas proximidades dos aeroportos os detritos orgânicos sejam tratados adequadamente e áreas com grande concentração desse tipo de material sejam eliminadas. $\mathrm{Na}$ Índia, um estudo mostrou que a remoção de carcaças 
em uma área de $100 \mathrm{~km}$ de raio a partir de um aeródromo civil pode resultar em uma diminuição da população de urubus (SATHËESAN; SATHEESAN, 2000).

Indivíduos da espécie $V$. chilensis também foram associados a um número considerável de eventos. Trata-se de uma ave que se alimenta de insetos e constrói ninhos em gramados e outras áreas de vegetação baixa (ANTAS; CAVALCANTI; CRUZ, 2009), tipos de ecossistemas comuns em aeroportos. A remoção de suas populações dos sítios aeroportuários utilizando métodos para afugentá-las e o uso de técnicas de manejo ambiental que limitem a disponibilidade de recursos utilizados por elas podem ajudar a diminuir o número de colisões dessa espécie com aeronaves. Manter a vegetação um pouco mais alta do que o habitual é uma técnica utilizada para tornar os sítios aeroportuários não atrativos para espécies que se alimentam em áreas de vegetação rasteira (DEACON; ROCHARD, 2000). Tal estratégia, no entanto, deve ser implementada com cuidado, pois ela pode ter - efeito colateral de atrair pequenos mamíferos e as aves que os predam (SODHI, 2002).

Fregata magnificens é uma ave marinha que ocorre na maior parte da costa brasileira, incluindo o Rio de Janeiro (SIGRIST, 2009). Na capital desse estado, local de onde vieram os sete materiais associados à espécie, os dois maiores aeroportos localizam-se à beira-mar e, sendo assim, evitar choques de aeronaves com indivíduos de $F$. magnificens representa um problema extremamente complexo. O monitoramento das populações locais da espécie para avaliar e eventualmente prevenir o seu crescimento além dos níveis normais, bem como o estabelecimento de regras para que barcos pesqueiros, potencialmente atrativos para estas aves, não se aproximem dos aeroportos, estão entre as possíveis ações que podem ser adotadas.

Importa mencionar que alíquotas do DNA extraído de todas as amostras dos materiais analisados encontram-se identificadas e armazenadas no Laboratório de DNA da Polícia Federal em Brasília para a eventual necessidade de novas análises.

Tabela 1 - Espécies e gêneros identificados a partir dos materiais encaminhados para exame (Materiais) e sua relação com o número de ocorrências de colisões com aeronaves entre os anos de 2014 e 2018 (Eventos) e as localidades onde aconteceram

\begin{tabular}{|c|c|c|c|}
\hline Identidade & Materiais (n) & Eventos (n) & Localidade \\
\hline $\begin{array}{l}\text { Coragyps atratus (Cathathiformes, } \\
\text { Catharthidae), urubu }\end{array}$ & 37 & 37 & $\begin{array}{l}\text { Canoas (RS), região central do } \\
\text { RS; Campinas, Guarulhos, } \\
\text { Jundiaí, Pirassununga, São José } \\
\text { do Rio Preto, São Paulo (SP); Rio } \\
\text { das Ostras, Rio de Janeiro (RJ); } \\
\text { São Francisco Sales (MG); } \\
\text { Goiânia (GO); Ilhéus, Salvador } \\
\text { (BA); Parnamirim, São Gonçalo do } \\
\text { Amarante (RN); Fortaleza (CE); } \\
\text { Belém (PA); Santo Antônio do } \\
\text { Matupi (AM); Porto Velho (RO); } \\
\text { Boa Vista (RR), }\end{array}$ \\
\hline $\begin{array}{l}\text { Caracara plancus (Falconiformes, } \\
\text { Falconidae), carcará }\end{array}$ & 16 & 15 & 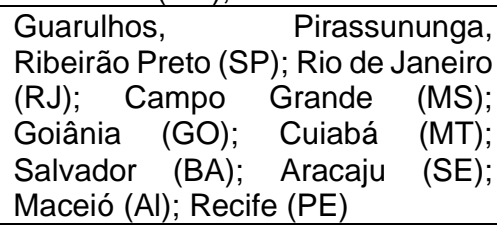 \\
\hline $\begin{array}{l}\text { Vanellus chilensis (Charadriiformes, } \\
\text { Charadriidae), quero-quero }\end{array}$ & 9 & 9 & $\begin{array}{l}\text { Santa Maria (RS); Joinville (SC); } \\
\text { Londrina (PR); Campinas, } \\
\text { Pirassununga (SP); Rio de Janeiro } \\
\text { (RJ); Campina Grande (PB); } \\
\text { Belém (PA) }\end{array}$ \\
\hline $\begin{array}{l}\text { Fregata magnificens (Suliformes, } \\
\text { Fregatidae), tesourão }\end{array}$ & 7 & 7 & Rio de Janeiro (RJ) \\
\hline $\begin{array}{l}\text { Columba livia (Columbiformes, } \\
\text { Columbidae), pombo-doméstico }\end{array}$ & 3 & 3 & Fortaleza (CE) \\
\hline Cypseloides sp. (Apodiformes, & 2 & 1 & Rio de Janeiro (RJ) \\
\hline
\end{tabular}

Apodidae) $)^{1}$ 
REA - Revista de estudos ambientais (Online)

v.21, n. 2, p.71-79, jul./dez. 2019

Tabela 1 - Espécies e gêneros identificados a partir dos materiais encaminhados para exame (Materiais) e sua relação com o número de ocorrências de colisões com aeronaves entre os anos de 2014 e 2018 (Eventos) e as localidades onde aconteceram

\begin{tabular}{|c|c|c|c|}
\hline Identidade & Materiais (n) & Eventos (n) & Localidade \\
\hline $\begin{array}{l}\text { Patagioenas picazuro } \\
\text { (Columbiformes, Columbidae), asa- } \\
\text { branca }\end{array}$ & 2 & 2 & $\begin{array}{l}\text { São José dos Campos, São José } \\
\text { do Rio Preto (SP) }\end{array}$ \\
\hline $\begin{array}{l}\text { Vanellus chilensis (Charadriiformes, } \\
\text { Charadriidae), quero-quero; } \\
\text { Coturnix coturnix (Galliformes, } \\
\text { Phasianidae), codorna }{ }^{2} \\
\end{array}$ & 1 & 1 & Rio de Janeiro (RJ) \\
\hline $\begin{array}{l}\text { Galus gallus (Galliformes, } \\
\text { Phasianidae), galinha }\end{array}$ & 1 & 1 & $\begin{array}{l}\text { Rota aérea entre Recife (PE) e } \\
\text { Anápolis }(G O)\end{array}$ \\
\hline $\begin{array}{l}\text { Hydropsalis torquata } \\
\text { (Caprimulgiformes, Caprimulgidae), } \\
\text { bacurau-tesoura }\end{array}$ & 1 & 1 & Corumbá (MS) \\
\hline $\begin{array}{l}\text { Numida meleagris (Galliformes, } \\
\text { Numididae), galinha d'angola }\end{array}$ & 1 & 1 & Maringá (PR) \\
\hline $\begin{array}{l}\text { Tachycineta albiventer } \\
\text { (Passeriformes, Hirundinidae), } \\
\text { andorinha-do-rio }\end{array}$ & 1 & 1 & Natal $(\mathrm{RN})$ \\
\hline $\begin{array}{l}\text { Tyrannus melancholicus } \\
\text { (Passeriformes, Tyrannidae), suiriri }\end{array}$ & 1 & 1 & Manaus (AM) \\
\hline $\begin{array}{l}\text { Caracara sp. (Falconiformes, } \\
\text { Falconidae) }^{3}\end{array}$ & 1 & 1 & Belém (PA) \\
\hline $\begin{array}{l}\text { Anhinga anhinga (Suliformes, } \\
\text { Anhingidae), biguatinga }\end{array}$ & 1 & 1 & Manaus (AM) \\
\hline $\begin{array}{l}\text { Cathartes burrovianus } \\
\text { (Cathathiformes, Catharthidae), } \\
\text { urubu-de-cabeça-amarela }\end{array}$ & 1 & 1 & Campina Grande (PB) \\
\hline $\begin{array}{l}\text { Hirundo rustica (Passeriformes, } \\
\text { Hirundinidae), andorinha-de-bando }\end{array}$ & 1 & 1 & Pirassununga (SP) \\
\hline $\begin{array}{l}\text { Athene cunicularia (Strigiformes, } \\
\text { Strigidae), coruja-buraqueira }\end{array}$ & 1 & 1 & Campo Grande (MS) \\
\hline $\begin{array}{l}\text { Nannopterum brasilianus } \\
\text { (Suliformes, Phalacrocoracidae), } \\
\text { biguá }\end{array}$ & 1 & 1 & Rio de Janeiro (RJ) \\
\hline $\begin{array}{l}\text { Tyto furcata (Strigiformes, } \\
\text { Tytonidae), suindara }\end{array}$ & 1 & 1 & Anápolis (GO) \\
\hline $\begin{array}{l}\text { Zenaida auriculata (Columbiformes, } \\
\text { Columbidae), avoante }\end{array}$ & 1 & 1 & Anápolis (GO) \\
\hline $\begin{array}{l}\text { Patagioenas cayennensis } \\
\text { (Columbiformes, Columbidae), } \\
\text { pomba-galega }\end{array}$ & 1 & 1 & Anápolis (GO) \\
\hline Não identificado & 18 & 8 & $\begin{array}{l}\text { Rio de Janeiro, São Pedro d'Aldeia } \\
\text { (RJ); Miranda (MS); Anápolis } \\
\text { (GO); Brasília (DF); Recife (PE) }\end{array}$ \\
\hline Total & 109 & 97 & \\
\hline
\end{tabular}

${ }^{1}$ Espécies congenéricas que ocorrem na localidade dos eventos não estão representadas no BOLD.

${ }^{2} V$. chilensis e $C$. japononica foram identificados a partir de duas amostras diferentes do mesmo material (suabes da mesma mancha na aeronave).

${ }^{3}$ A sequência apresentou mais de $99 \%$ de similaridade com as duas espécies do gênero, sendo que as duas ocorrem no local do evento.

Fonte: Autores (2019)

\section{Conclusões}

Tendo em vista a natureza dos materiais recebidos para exames, sem o uso de técnicas moleculares as espécies envolvidas em diversas colisões entre aves e aeronaves dificilmente seriam identificadas.
Individualmente, a identidade de cada ave forneceu elementos para 0 auxílio das investigações em curso e, em conjunto, os dados permitem especular sobre a existência de determinados padrões, como por exemplo - fato de que apenas algumas poucas espécies estariam envolvidas na maior parte 
dos eventos de colisões. Embora estudos com um maior número de amostras e que considerem especificidades regionais e locais sejam necessários para corroborar os resultados aqui obtidos, é inegável que o DNA barcoding e o BOLD são ferramentas que podem contribuir bastante para a prevenção de acidentes aéreos e para a melhoria da segurança de voo no Brasil.

\title{
5 Investigating Bird Strikes in Brazil through DNA Barcoding
}

\begin{abstract}
Collisions between birds and aircraft frequent worldwide, threatening lives and causing economic losses. The identification of birds that collide with aircrafts is important to assist accident investigations and to support management plans to reduce risks in critical areas. When morphology cannot be used, bird remains can be identified through DNA barcoding, an animal identification system based on cytochrome $c$ oxidase I mitochondrial gene (COI) sequences that vary between species. Currently, the system has a computerized platform named BOLD, which includes a reference database with authenticated sequences and a searching engine used for species identification. Between 2014 and 2018, the Federal Police DNA Laboratory received for identification purposes from the Center for Research and Prevention of Aeronautical Accidents (CENIPA) 109 materials related to 97 different bird strike events. DNA Barcoding and BOLD, associated with species occurrence data, allowed the identification of $83.5 \%$ materials, pointing the bird species of $91.7 \%$ bird strike events. In total, twenty-three species or genera were identified. Coragyps atratus, Caracara plancus, Vanellus chilensis e Fregata magnificens were the most frequent species. Apparently, a few species are involved in most bird strikes, and thus actions that aim to reduce the risk of these events should prioritize them.
\end{abstract}

Keywords: DNA Barcoding; Bird strikes; Identification; Aircraft.

\section{Referências}

ALACS, E. A.; GEORGES, A.; FITZSIMMONS, N. N.; ROBERTSON, J. DNA detective: a review of molecular approaches to wildlife forensics. Forensic Science Medicine Pathology. v. 6, n. 3, p. 180-194, 2010.

ANTAS, P. T. Z.; CAVALCANTI, R. B; CRUZ, M. C. V. Aves comuns do Planalto Central. 1. ed. Brasília: Editora Universidade de Brasília. 2009, $270 \mathrm{p}$.

ALLAN, J. R. The costs of bird strikes and bird strike prevention. In: HUMAN CONFLICTS WITH WILDLIFE: ECONOMIC CONSIDERATIONS. NATIONAL WILDLIFE RESEARCH CENTER SYMPOSIA, 2000 Lincoln, NE, EUA. Anais... Lincoln, NE, EUA: NATIONAL WILDLIFE RESEARCH CENTER, 2005. p. 147-153.

ANDERSON, A.; CARPENTER, D. S.; BEGIER, M. J.; BLACKWELL, B. F.; DEVAULT, T. L.; SHWIFF, S. A. Modeling the cost of bird strikes to US civil aircraft. Transportation Research Part D. v. 38: p. 49-58, 2015.

ARAUJO, G. M.; PERES C. A.; BACCARO, F. B.; GUERTA, R. S. Urban waste disposal explains the distribution of Black Vultures (Coragyps atratus) in an Amazonian metropolis: management implications for birdstrikes and urban planning. PeerJ. 6: e5491, 2018.

CARVALHO, C. B. V. DNA Barcoding in Forensic Vertebrate Species Identification. Brazilian
Journal of Forensic Sciences Medical Law and Bioethics. v. 4, n.1, p. 12-23, 2014.

DANWAY, N.; OGDEN, R.; MC EWING, R.; CARVALHO, G. R.; THORPE, R. S. Validation of the Barcoding gene $\mathrm{COI}$ for use in forensic genetic species identification. Forensic Science International. v. 173, p. 1-6, 2007.

DEACON, N.; ROCHARD, B. Fifty years of airfield grass management in the UK. In: INTERNATIONAL BIRD STRIKE COMMITTEE MEETING, 25., 2000, Amsterdam, Holanda. Anais... Amsterdam, Holanda: International Bird Strike Committee, 2000. p. 1-9.

DOLBEER, R. A.; WRIGHT, S. E.; WELLER, J.; BEGIER, M. J. Wildlife strikes to civil aircraft in the United States, 1990-2015. U.S. Department of Transportation, Federal Aviation Administration, Office of Airport Safety and Standards, Serial Report No. 22. Washington, DC, 2013. 102 p.

DOVE, C. J.; DAHLAN, N. F.; HEACKER, M. Forensic bird-strike identification techniques used in an accident investigation at Wiley Post Airport, Oklahoma, 2008. Human-Wildlife Interactions. v. 3, n. 2, p. 179-185, 2009.

DOVE, C. J.; ROTZEL, N. C.; HEACKER, M.; WEIGT, L. A. Using DNA Barcodes to Identify Bird Species Involved in Birdstrikes. Journal of Wildlife Management. v. 72, n. 5, p 1231-1236, 2008. 


\section{REA - Revista de estudos ambientais (Online) v.21, n. 2, p.71-79, jul./dez. 2019}

FOLMER, O.; BLACK, M.; HOEH, W.; LUTZ, R.; VRIJENHOEK, R. DNA primers for amplification of mitochondrial cytochrome c oxidase subunit I from diverse metazoan invertebrates. Molecular Marine Biology and Biotechnology v. 3, p. 294-299, 1994.

GILL, F.; DONSKER, D. IOC World Bird List (v 9.1). 2019. Disponível em: http://www.worldbirdnames.org/. Acesso em: 17 mar. 2019.

HERBERT, P. D. N.; STOECKLE, M. Y.; ZEMLAK, T. S.; FRANCIS, C. M. Identification of Birds through DNA Barcodes. PLoS Biology. v. 2, n. 10, p. $1657-1663,2004$.

HERBERT, P. D. N.; RATNASINGHAM, S.; WAARD, J. R. Barcoding animal life: cytochrome $C$ oxidase subunit 1 divergences among closely related species. Proceedings of the Royal Society of London B. v. 270, p. 96-99, 2003.

JOHNSON R. N.; WILSON-WILDE, L.; LINACRE, A wildlife forensic science. Forensic Science International Genetics. v. 10, p. 1-11, 2014.

LINACRE, A.; TOBE, S. S. An overview to the investigative approach to species testing in wildlife forensic science. Investigative Genetics. v. 2, n. 1, p.2, 2011.

MARTOS, J. F. A.; MADEIRA, F. Análise das Medidas de Controle do Perigo Aviário. In: Simpósio de Segurança de Voo, 6., 2013, São José do Campos. Anais...São José dos Campos: Instituto de Pesquisas e Ensaios em Voo. 2013. p. 1000-1014.

MENQ, W. Caracará (Caracara plancus) - Aves de Rapina Brasil. 2018. Disponível em: http://www.avesderapinabrasil.com/caracara plan cus.htm. Acesso em: 28 nov. 2019.

MICHELIN. K.; FREITAS, J. M.; KORTMANN, G. L. Vistígios Biológicos. In: VELHO, J. A.; COSTA, K. A.; DAMASCENO, T. M. Locais de Crime. Campinas: Millennium. 2013. p. 83-124.

OGDEN, R.; DAWNAY, N.; MCEWING, R. Wildlife DNA forensics - bridging the gap between conservation genetics and law enforcement. Endangered Species Research. v. 9, p. 179-195, 2009.

OLIVEIRA, H. R. B; SANTOS, L. C. B.; OLIVEIRA, C. M.; SILVA, J.P. Anuário de Risco de Fauna 2015. Centro de Investigação e Prevenção de Acidentes Aeronáuticos (CENIPA). Brasília, DF, 2016. $49 \mathrm{p}$

OLIVEIRA, H. S.; SOUZA, D. R. A.; SILVA, M. N. Etograma do Carcará (Caracara Plancus, Miller, 1777) (Aves, Falconidae), em cativeiro. Revista de Etologia. v. 13, n. 2, p. 1-9, 2014.
PIACENTINI, V. Q.; ALEIXO, A.; AGNE, C. E.; MAURÍCIO, G. N.; PACHECO, J. F.; BRAVO, G. A.; BRITO, G. R. R.; NAKA, L. N.; OLMOS, F.; POSSO, S.; SILVEIRA, L. F.; BETINI, G.; CARRANO, E.; FRANZ, I.; MOREIRA-LIMA, L.; LEES, A. C.; PIOLI, D.; SCHUNCK, F.; AMARAL, F. R.; BENCKE, G.; COHN-HAFT, M.; FIGUEIREDO, L. F.; STRAUBE, F. C.; CESARI, E. Annotated checklist of the birds of Brazil by the Brazilian Ornithological Records Committee/Lista comentada das aves do Brasil pelo Comitê Brasileiro de Registros Ornitológicos. Revista Brasileira de Ornitologia. v 23, p. 91-298, 2015.

RATNASINGHAM, S.; HEBERT, P. D. N. BARCODE OF LIFE DATA SYSTEM v4. 2019. Disponível em <http://www.boldsystems.org/>. Acesso em: 17 março 2019.

RATNASINGHAM, S.; HEBERT, P. D. N. BOLD: The Barcode of Life Data System (www.barcodinglife.org). Molecular Ecology Notes. v. 7, p. 355-364, 2007.

RISCO de colisões entre aviões e aves cresce e ameaça à segurança. Revista de audiências públicas do Senado Federal. Revista em Discussão, Brasília, v. 1, n. 5, p. 68-72, 2010.

SATHEESAN, S. M.; SATHEESAN, M. SERIOUS VULTURE-HITS TO AIRCRAFT OVER THE WORLD. In: INTERNATIONAL BIRD STRIKE COMMITTEE MEETING, 25., 2000, Amsterdam, Holanda. Anais... Amsterdam, Holanda: International Bird Strike Committee, 2000. p. 114126.

SEQSCAPE 3 SOFTWARE. Life Technologies Corporation, 2012. 1 CD.

SIGRIST, T. Guia de Campo Avis Brasilis. Avifauna Brasileira. 1. ed. São Paulo: Avis Brasilis. 2009, 480 p.

SODHI, N. S. Competition on the air: birds versus aircraft. Auk. v. 119, n. 3, p. 587-595, 2002.

TAMURA, K.; STECHER, G.; PETERSON, D.; FILIPSKI, A.; KUMAR, S. MEGA6: Molecular Evolutionary Genetics Analysis version 6.0. Molecular Biology and Evolution. v. 30, p. 2725-2729, 2013.

TAVARES, E. S.; GONÇALVES, P.; MIYAKI, C. Y.; BAKER, A. J. DNA Barcode Detects High Genetic Structure within Neotropical Bird Species. PLoS One. v. 6, n. 12, p 1-13, 2011

WARD, R. D.; ZEMLAK, T. S.; INNES, B. H.; LAST, P. R.; HERBERT, P. D. N. DNA barcoding Autralia's fish species. Philosophical Transactions of the Royal Society B. v. 360, p. 1847-1857, 2005.

WAUGH, J.; EVANS, M. W.; MILLAR, C. D.; LAMBERT, D. Birdstrikes and barcoding: Can DNA 
REA - Revista de estudos ambientais (Online)

v.21, n. 2, p.71-79, jul./dez. 2019

methods help make the airways safer? Molecular Ecology Resources. v.11, p. 38-45, 2011.

\section{Agradecimentos}

Os autores agradecem aos colegas Peritos Criminais Federais que revisaram muitas das análises que resultaram nas identificações aqui apresentadas e o apoio institucional da Diretoria Técnico-Cientifica (DITEC) e do Instituto Nacional de
Criminalística (INC) da Polícia Federal. Agradecem também o apoio da Fundação de Amparo à Pesquisa do Distrito Federal (FAPDF), que financiou a apresentação de um trabalho com os resultados iniciais desse projeto de cooperação entre o CENIPA e a Polícia Federal em evento internacional. Por fim, agradecem também aos revisores anônimos, cujos comentários e sugestões contribuíram bastante para a melhoria do artigo. 